\title{
FORMAL THEORIES OF EXTENSION AND INTENSION OF EXPRESSIONS
}

(Summary)

\begin{abstract}
An endeavour to systematize those conceptual constructions in formal logic which in modern semantics are used to explain the traditional concepts of extension (denotation) and intension (meaning, connotation) of expressions. A general scheme and the consecutive steps of the theoretical procedure usually used for that purpose are described. The examples discussed are the constructions of R. CARNAP introduced in his theory of extension and intension, and the concepts of R. SUSZKO and E. W. BETH, partly modelled on Carnap's ideas. The differences as between the concepts of the various authors are discussed. Possible modifications of those concepts, within the limits of their common schema of theoretical procedure, are also indicated.
\end{abstract}

